\title{
Generation and propagation of static displacement estimated using KiK-net recordings
}

\author{
Shigeo Kinoshita and Makiko Takagishi \\ Yokohama City University, Seto 22-2, Kanazawa-ku, Yokohama 236-0027, Japan
}

(Received April 7, 2011; Revised April 25, 2011; Accepted May 1, 2011; Online published September 27, 2011)

\begin{abstract}
Using KiK-net strong-motion data recorded at eleven stations during the 2011 off the Pacific coast of Tohoku Earthquake (the 2011 Tohoku Earthquake), we investigate the generation and propagation of static displacements, i.e. coseismic permanent near-field displacements. The static displacements are calculated by double numerical integration after removing acceleration steps from the acceleration signals. The estimated static displacements are totally in agreement with the land deformation measured by GEONET, the GPS network established by the Geographical Survey Institute, despite the fact that our estimation method is extremely simple. It is hoped that scientific studies of this disastrous earthquake will one day lead to a real-time evaluation system for static displacement using strong-motion data. This would be expected to greatly improve the effectiveness of tsunami alert systems, since tsunamis are caused by sea-floor movements during earthquakes.
\end{abstract}

Key words: Static displacement, strong-motion, KiK-net.

\section{Introduction}

This short article reports a preliminary evaluation of displacement signals estimated using borehole data provided by the KiK-net (Okada et al., 2004) of the NIED (National Research Institute for Earth Science and Disaster Prevention) for the 2011 Tohoku Earthquake. Given the magnitude of this event $\left(M_{\mathrm{w}}=9.0\right)$, the strong-motion records may be quite different from previous records. The generation and propagation of static displacement are evaluated based on near-field recordings.

GEONET, the Global Positioning System (GPS) established by the Geographical Survey Institute (GSI), recorded land deformation up to approximately 5 meters at the Pacific coast of eastern Honshu; in addition, an east-southeast deformation of 5.3 meters and a downward deformation of 1.2 meters were measured at the Ojika GPS site. Such coseismic permanent displacement, i.e. near-field static displacement, and its spatial distribution, can lead to a tilt step in near-field acceleration signals as shown by Pillet and Virieux (2007). Furthermore, local tilt motions due to soil deformation may be induced by strong shaking (Kinoshita, 2008). The simplest method of modeling such tilt motion in the acceleration signals is based on a step increase in acceleration approximated by a Heaviside step function (Zahradnik and Plesinger, 2005; Pillet and Virieux, 2007). This model produces a linearly increasing velocity signal by numerically integrating the acceleration signal. An acceleration step with a finite rise time, of course, causes a tradeoff between the tilt and static displacement signals (Kinoshita et al., 2009). Thus, we evaluated the static displacement

Copyright (c) The Society of Geomagnetism and Earth, Planetary and Space Sciences (SGEPSS); The Seismological Society of Japan; The Volcanological Society of Japan; The Geodetic Society of Japan; The Japanese Society for Planetary Sciences; TERRAPUB.

doi:10.5047/eps.2011.05.003 by removing the influence of a Heaviside-type acceleration step.

The estimated displacement signals at eleven KiK-net stations indicate the generation of static displacements, which is totally in agreement with the land deformation measured by GEONET and published on the Internet (http://www.gsi.go.jp/).

\section{Data and Method}

To evaluate near-field displacement signals for this earthquake, we selected strong-motion data recorded at eleven relatively equispaced KiK-net stations in the region between the northern boundary of Iwate Prefecture and the southern boundary of Ibaraki Prefecture, as shown in Fig. 1 and Table 1; the data are provided on the Web site of KiKnet (http://www.bosai.go.jp/). The data for each station correspond to an accelerogram recorded at the top and bottom of a borehole. With the exception of the IBRH20 site, the borehole bottom recordings are used to estimate static displacements. For the IBRH20 site, the surface signal is used since the borehole depth at this site is rather large.

In this study, a conventional method is used for calculating the displacement signal from the acceleration signal (Zahradnik and Plesinger, 2005; Pillet and Virieux, 2007), assuming an acceleration step of the form $a H\left(t-t_{\mathrm{o}}\right)$ in the accelerogram, where $a, H$ and $t_{\mathrm{o}}$ represent the amplitude of the acceleration step, the Heaviside step function and the onset time of the step, respectively. The parameters $a$ and $t_{\mathrm{o}}$ are determined from a linearly-increasing velocity signal calculated by numerical integration of the acceleration signal. For example, Fig. 2(b) shows the velocity signal determined from the east-west acceleration signal shown in Fig. 2(a), which was recorded at the MYGH12 site. The dotted line in Fig. 2(b) is a linear fit to the velocity data window between 200 and $300 \mathrm{~s}$, and $a$ and $t_{\mathrm{o}}$ are deter- 
Table 1. Station data used in this study and mean static displacements estimated. Acceleration signals recorded at borehole bottoms at each site are used, with the exception of the IBRH20 site, for which surface signals are used.

\begin{tabular}{|c|c|c|c|c|c|c|c|c|c|}
\hline & Site code & Site name & Lat. (N) & Long. (E) & Height (m) & $\begin{array}{c}\text { Depth of } \\
\text { borehole }(\mathrm{m})\end{array}$ & $\begin{array}{c}\text { Static Disp. } \\
\text { Eest }(\mathrm{cm})\end{array}$ & $\begin{array}{l}\text { Static Disp. } \\
\text { North }(\mathrm{cm})\end{array}$ & $\begin{array}{c}\text { Static Disp. } \\
\text { Up }(\mathrm{cm})\end{array}$ \\
\hline 1 & FKSH12 & HIRATA & 37.2139 & 140.5736 & 470 & 105 & 164 & -48 & -25 \\
\hline 2 & FKSH19 & MIYAKOJI & 37.4672 & 140.7261 & 510 & 100 & 188 & -39 & -45 \\
\hline 3 & IBRH14 & JYUUOH & 36.689 & 140.5518 & 330 & 100 & 110 & -2 & -29 \\
\hline 4 & IBRH20 & HASAKI2 & 35.8252 & 140.7356 & 6 & 0 & 12 & 13 & unstable \\
\hline 5 & IWTH08 & KUJI-N & 40.2658 & 141.7867 & 175 & 100 & 43 & -40 & -17 \\
\hline 6 & IWTH14 & TAROU & 39.7407 & 141.9123 & 200 & 100 & 121 & -95 & -16 \\
\hline 7 & IWTH21 & YAMADA & 39.4705 & 141.9372 & 13 & 100 & 166 & -170 & -38 \\
\hline 8 & MYGH03 & KARAKUWA & 38.9178 & 141.6412 & 80 & 117 & 368 & -201 & -72 \\
\hline 9 & MYGH06 & TAJIRI & 38.5878 & 141.0744 & 20 & 100 & 365 & -92 & -60 \\
\hline 10 & MYGH10 & YAMAMOTO & 37.9381 & 140.8958 & 18 & 205 & 280 & -23 & -58 \\
\hline 11 & MYGH12 & SHIZUGAWA & 38.6386 & 141.4463 & 18 & 102 & 428 & -161 & -83 \\
\hline
\end{tabular}

(a)

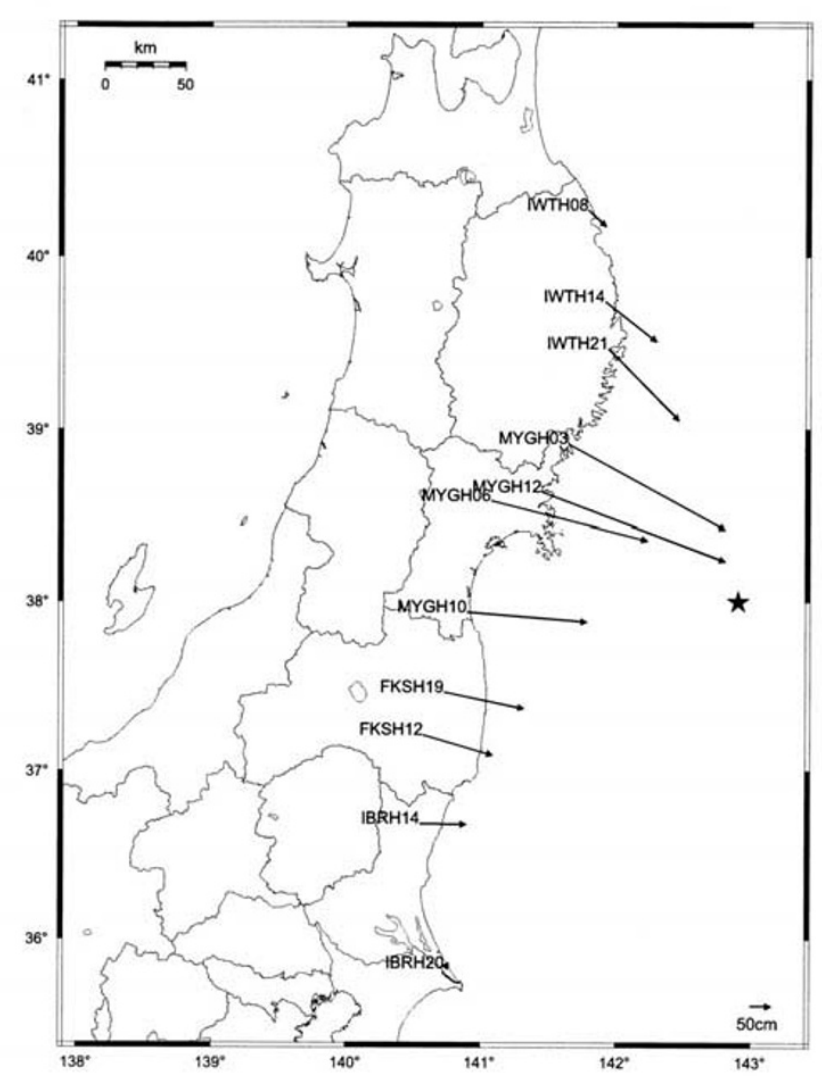

(b)

\section{Dispalcement (Vertical)}

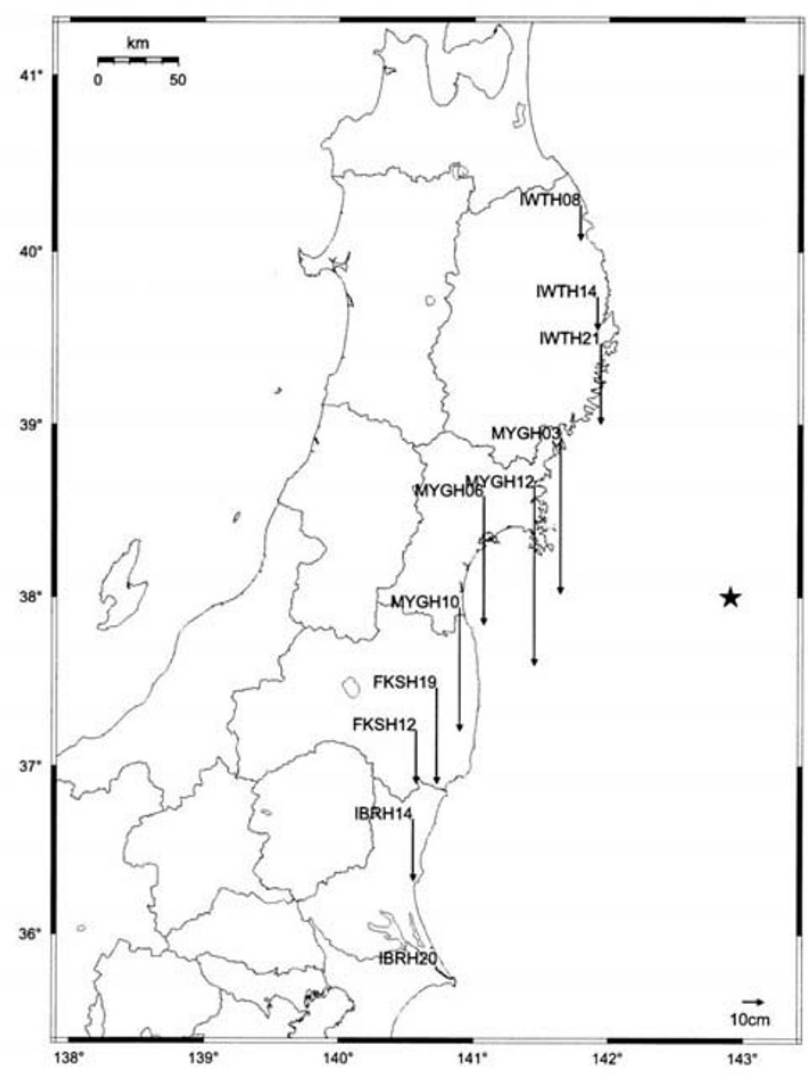

Fig. 1. Locations of KiK-net stations used in this study and estimated static displacements: (a) horizontal direction and (b) vertical direction. These static displacements are mean values calculated from displacement data in the data window from 200 to $300 \mathrm{~s}$.

mined from the gradient of this straight line and its intercept on the time axis, respectively. From acceleration signals compensated for the offset $a$ for $t \geq t_{\mathrm{o}}$, tilt-compensated velocity and displacement signals are calculated as shown in Figs. 2(c) and (d), respectively. As can be seen from Fig. 2(d), a static displacement of about 4 meters occurs in the eastward direction.

\section{Results}

Figures 3(a), (b) and (c) show the north-south, east-west and up-down components, respectively, of the displacement signals at the different stations. The displacement directions are eastward, southward and downward and the propagation of the static displacement can be clearly seen in these figures. Table 1 and Figs. 1(a) and (b) show the mean values of static displacement calculated from the displacement data window between 200 and $300 \mathrm{~s}$ in Figs. 3(a), (b) and (c). Static downward displacements of 0.5 to $1 \mathrm{~m}$ are observed at four sites in Miyagi Prefecture as shown in Table 1 and Fig. 1(b). The largest static displacements are in the eastward direction, with a displacement of almost $4 \mathrm{~m}$ observed at the MYGH12 site. These results shown in Figs. 1(a) and 


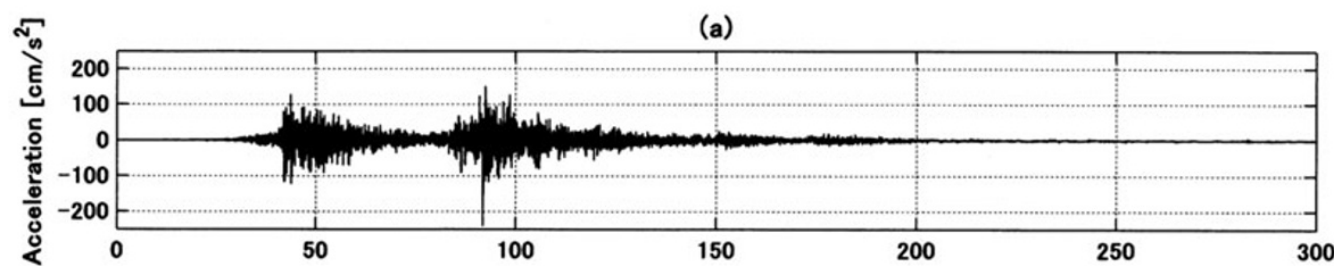

(b)

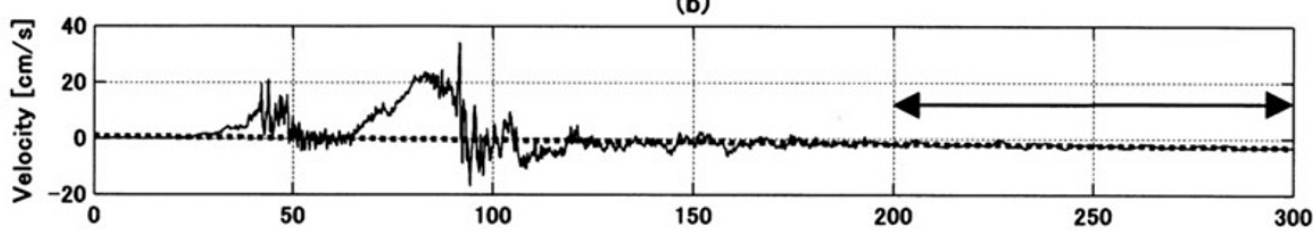

(c)

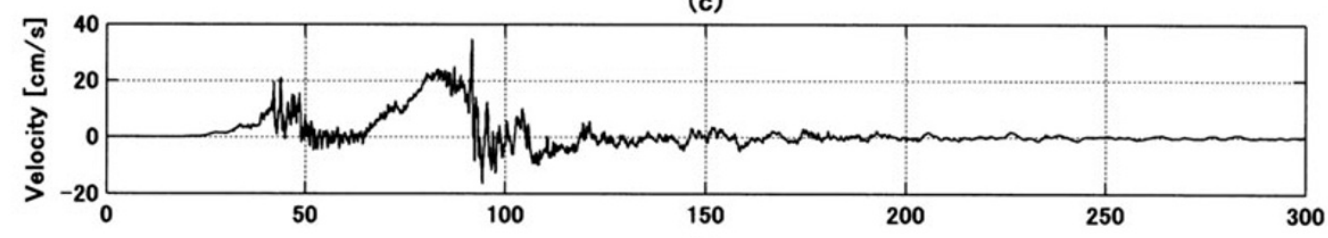

(d)

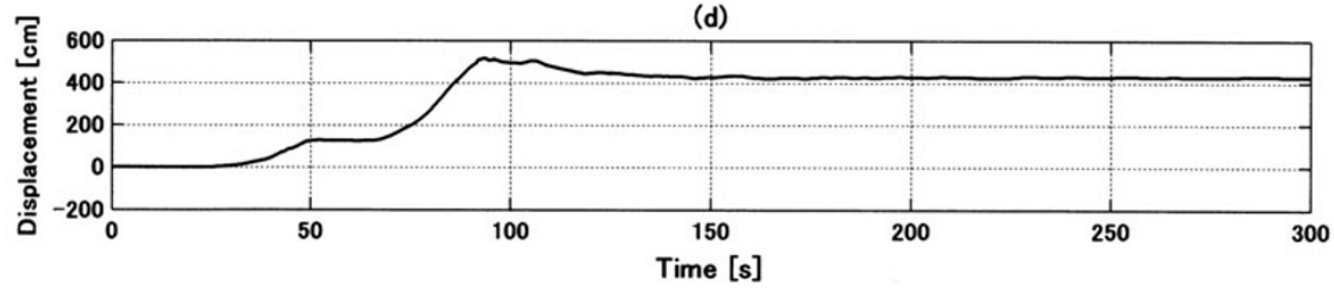

Fig. 2. Example of static displacement estimation: (a) east-west acceleration signal recorded at the MYGH12 site, (b) velocity signals (solid line) calculated by numerical integration of acceleration signal, and regression line (dotted) determined by fitting to the velocity signal in the data window from 200 to $300 \mathrm{~s}$ (indicated by arrows), (c) calculated tilt-compensated velocity signal, and (d) displacement signal calculated from velocity signal shown in (c). Coseismic permanent displacement, i.e., static displacement, of approximately $4 \mathrm{~m}$ in eastward direction is estimated.

(a)

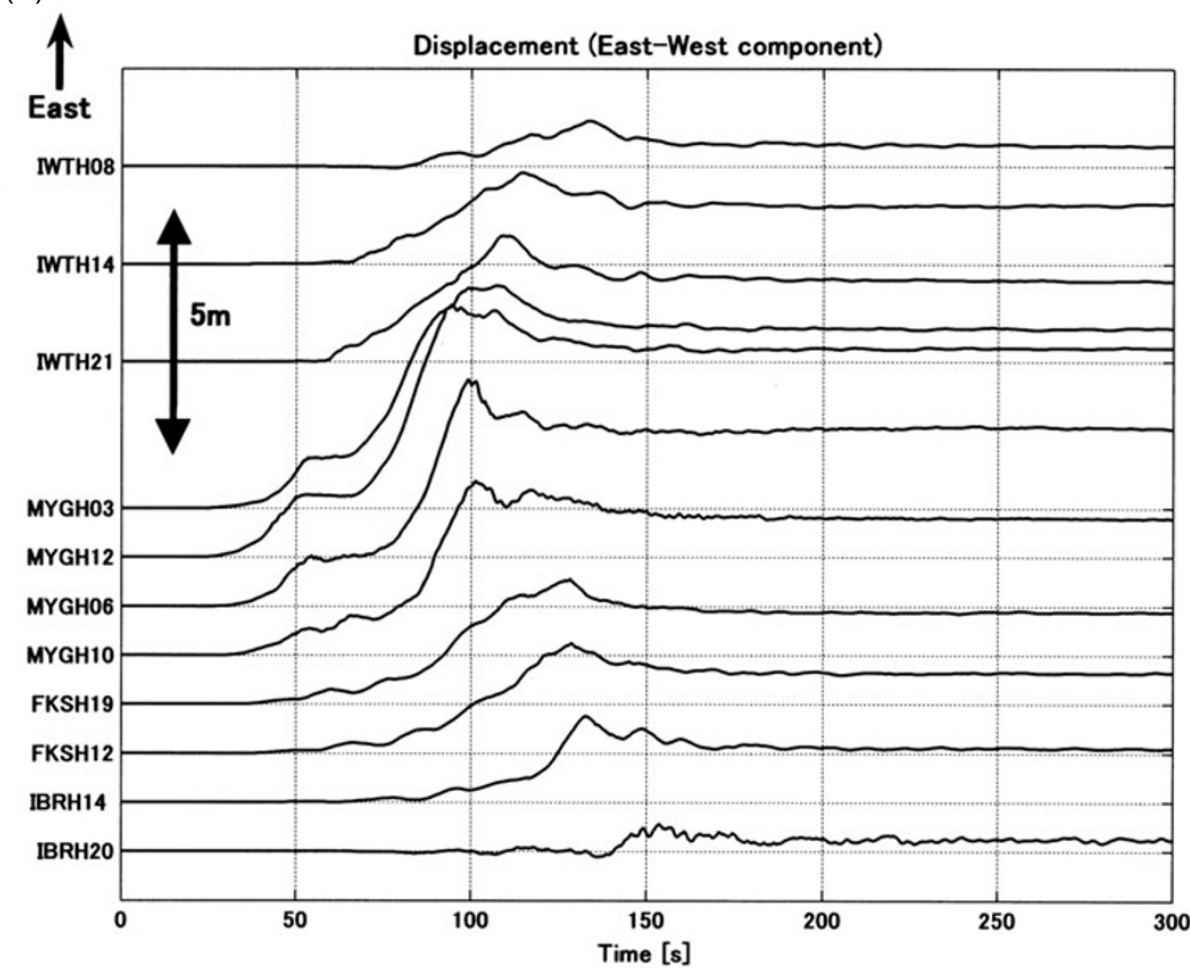

Fig. 3. Displacement signals estimated from borehole acceleration signals recorded at eleven KiK-net stations: (a) east-west, (b) north-south, and (c) up-down components. 
(b)

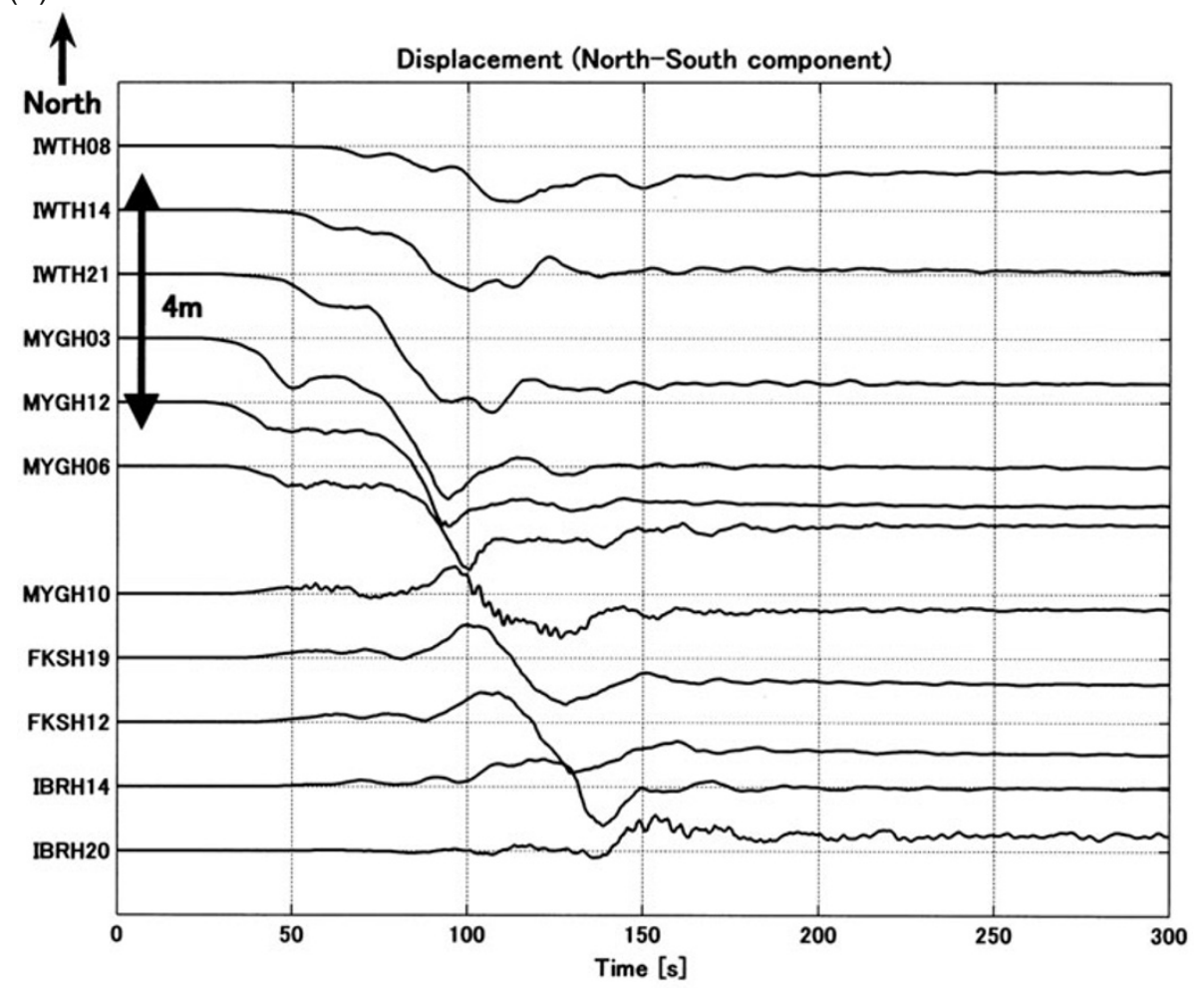

(c)

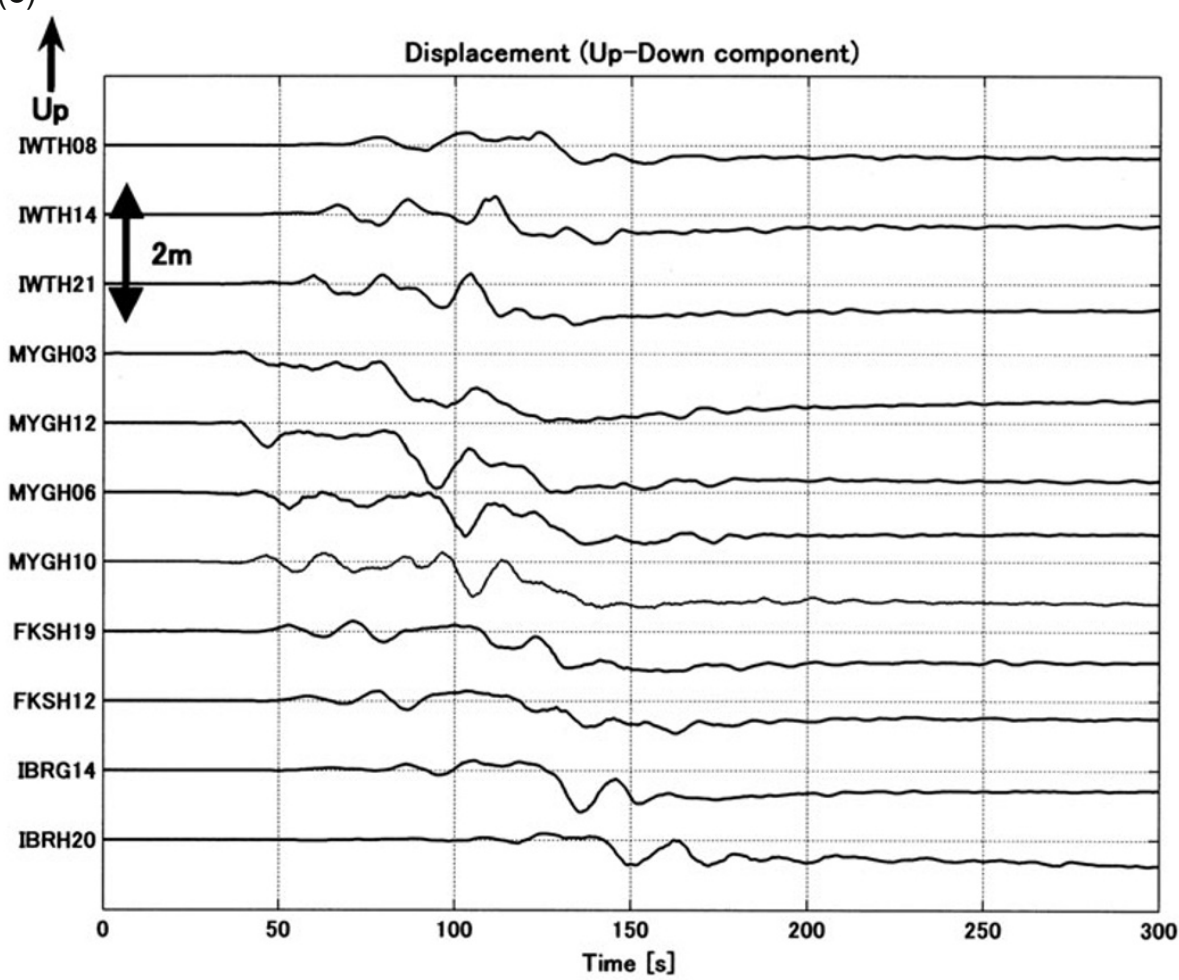

Fig. 3. (continued).

(b) are in full agreement with the GEONET measurements for land deformation just after the earthquake on the whole.

\section{Concluding Remarks}

As pointed out by Pillet and Virieux (2007), determining the gradient of the velocity signal cannot always be carried out accurately since a data length of $3 \mathrm{~min}$ is some- times too short for a reliable estimation of the gradient, and the maximum pre-event time of $15 \mathrm{~s}$ for KiK-net acceleration data may be insufficient for baseline estimation. In the present study, we used a common pre-event time of only $5 \mathrm{~s}$ to determine the baseline. However, the estimated static displacements closely match the GPS measurements just after the earthquake. This suggests that the strong-motion data 
obtained for this earthquake are probably more widely applicable than previous strong-motion records. For example, obtaining the static displacement from strong-motion data before the arrival of a tsunami would improve the reliability of tsunami alert systems, since tsunamis are caused by sea-floor movements during earthquakes. In addition, a knowledge of the downward static displacement may allow the length of the inundation period after the tsunami to be predicted. The possibility of mitigating tsunami disasters provides strong motivation to develop a real-time system for estimating static displacement.

Acknowledgments. The authors are grateful to Dr. Yusaku Ohta and an anonymous reviewer for carefully reviewing the manuscript. We thank Dr. Toshihiko Hayakawa for his help in preparing our manuscript. We would also like to thank the NIED for providing the KiK-net strong-motion data.

\section{References}

Kinoshita, S., Tilt measurement using broadband velocity seismograms, Bull. Seismol. Soc. Am., 98, 1887-1897, 2008.

Kinoshita, S., H. Ishikawa, and T. Satoh, Tilt motions recorded at two WISE sites for the 2003 Tokachi-Oki earthquake (M 8.3), Bull. Seismol. Soc. Am., 99(2B), 1251-1260, 2009.

Okada, Y., K. Kasahara, S. Hori, K. Obara, S. Sekiguchi, H. Fujiwara, and A. Yamamoto, Recent progress of seismic observation networks in Japan-Hi-net, F-net, K-NET and KiK-net—, Earth Planets Space, 56, xv-xxviii, 2004.

Pillet, R. and J. Virieux, The effects of seismic rotations on inertial sensors, Geophys. J. Int., 171(3), 1314-1323, 2007.

Zahradnik, J. and A. Plesinger, Long-period pulses in broadband records of near earthquakes, Bull. Seismol. Soc. Am., 95, 1928-939, 2005.

S. Kinoshita (e-mail: kkk001@yokohama-cu.ac.jp) and M. Takagishi 